Professor Paul Turner of USA told how he had studied anxious psychiatric patients and unexpectedly found that 'beta-blocker' drugs induced phenomenal improvement, reducing symptoms such as tremor, palpitations and excessive sweating. They have subsequently been found to be mercifully free of dependency and withdrawal problems, unlike, say, valium or alcohol. They have a real potential for situational anxiety, sometimes in small doses, but there are questions to be resolved as to whether reducing tension may also actually impair the quality of some musical performances. One concert pianist became so relaxed that her performance was reported as boring! Musicians need to experiment under medical supervision so as to discover their own appropriate lowest effective dose.

Dr Richard Pearson, medical director of a musicians' clinic recently opened in London, has diagnosed a surprisingly wide range of medical disorders which non-medical specialists could miss. For this reason, he explained, the clinic was established strictly under medical leadership, but in collaboration with various colleagues, both orthodox and alternative co-professionals, so as to make a wide range of treatment approaches available. During the conference feelings were expressed that its orientation is unbalanced, with insufficient attention to emotional aspects and an important need for musicians themselves to be included in the clinic panel.

Musicians are subject to a controversial condition, the Occupational Overuse Syndrome, which can destroy promising and successful careers. Several well-known pianists have been compelled to abandon playing altogether. An Australian plastic surgeon puts his faith in supplying prosthetic devices which, for example, help children distribute the weight of a modern clarinet ( 830 grams is too heavy to support on a child's thumb) and free a violinist's neck and chin, enabling players to move more easily as necessary, with reduction of stress. Prevention avoids the necessity for later treatment, which can be lengthy and difficult, with a demanding 'rest programme' in which all movements against resistance are forbidden. Carola Grindea, editor of the European Piano Journal and founder of ISSTIP, is the leading spirit behind the movement. She stresses that troubles arise from misuse of muscles, re-education repeatedly leading to cure even in serious cases.

In a lively disputation, Mr Campbell Semple, a Scots hand surgeon, expressed scepticism as to whether over-use of a properly trained hand is possible at all! He finds psychological elements prominent, but despite the presence of a variety of therapists, there did not appear to be any psychiatrists participating in the presentations at this conference. Yet mind/body interactions are of central importance in treating these complex disorders, which might prove a fruitful field of study for some musical psychiatrists. The mental sciences were represented by Jolanta Ossetin, a pianist and clinical psychologist at the Institute of Psychiatry. She suggested that many talented individuals become lost to the performing professions because they cannot cope with performance anxiety, partly due to personality characteristics, which tend to be overlooked altogether by the colleges in drawing up otherwise severe criteria for selection of future performers. She emphasised this responsibility for educators and reviewed the role of cognitive therapies in altering how individuals appraise themselves and perceive potentially threatening situations. She concluded that destructive thinking processes produce performance anxiety and without intervention in this sphere, other approaches are unlikely to yield lasting results. Other participants too cautioned against emphasising one particular problem and over-looking others which frequently co-exist.

The proceedings of this stimulating conference will become available in the ISSTIP Journal and should contribute to a greater awareness of the particular medical and emotional problems likely to be encountered during a performing career.

Further information about ISSTIP can be obtained from Carola Grindea, 28 Emperor's Gate, London SW7 4HS.

\title{
Mental Hospital Closures Campaign
}

On 8 March 1988 the National Schizophrenia Fellowship launched a campaign in the Houses of Parliament in a bid to halt the closure of mental hospitals until alternative care is available for patients in the community.

The campaign calls for, among other things, a Minister for Community Care whose task in Government will be to ensure that proper community care becomes a reality; one key worker in each community to whom patients are referred when they leave hospital; help for local authorities to provide suitable housing; a 24-hour emergency line for relatives to ring when they need urgent help in coping with patients; and the retention of a considerable number of existing mental hospitals to provide short-term treatment in case of serious relapse and long-term asylum for those who cannot cope outside.

The NSF and its supporters will be seeking to enrol the support of psychiatrists, doctors, nurses, health administrators, the police, magistrates, health service professional bodies and trade unions, local authorities and community groups. 